\title{
A AUTONOMIA NA EDUCAÇÃO A DISTÂNCIA
}

Talita Tardivo Rainha, Maria Luisa Furlan da Costa

Universidade Estadual de Maringá - UEM, Maringá, PR. E-mail: talita.rainha@hotmail.com

\section{RESUMO}

A proposta do presente artigo é elencar algumas das principais características da concepção de autonomia vinculada à Educação a Distância (EaD). No âmbito das teorias dessa área, esse conceito se diferencia fundamentalmente pelo desenvolvimento dos ambientes online. A concepção de autonomia em EaD trata-se de um modo de relacionamento complexo, com conteúdos e ferramentas interativas, disponíveis sobretudo em Ambientes Virtuais de Aprendizagem (AVAs). Será abordado, ainda que de maneira breve, os principais aspectos de três importantes teorias da área. O objetivo é de avançar na compreensão sobre o conceito de autonomia em EaD e nas peculiaridades que a educação mediada por tecnologias apresenta.

Palavras-chave: Autonomia; Educação a Distância; Aprendizagem online.

\section{THE AUTONOMY IN DISTANCE EDUCATION}

\begin{abstract}
The aim of this article is to list some of the main features of autonomy linked to Distance Education (DE-EaD). Within the scope of theories of this area, this concept is fundamentally different by the development of online environments. The concept of autonomy in Distance Education is a way of complex relationship with content and interactive tools, especially in Virtual Learning Environments (VLEs-AVAs) available. Will be addressed, albeit briefly, the main aspects of three important theories. The goal is to advance in the understanding of the concept of autonomy in Distance Education and the peculiarities that education mediated by technology presents.
\end{abstract}

Keywords: Autonomy; Distance Education; Online learning. 


\section{INTRODUÇÃO}

O conceito de autonomia tem sido construído historicamente no contexto de diferentes características culturais, econômicas e políticas que configuram as sociedades ao longo de seu percurso. Enquanto concepção política do pensamento grego, o termo autônomos (autós: por si mesmo e nomos: lei) refere-se ao poder de dar a si mesmo a própria lei em oposição à heteronomia (hetero: outro e nomos: lei), que traz o sentido de imposição de uma lei procedida por outra.

A vinculação entre os objetivos do processo educacional e os ideais de autonomia aparece como um elemento comum nos mais variados discursos pedagógicos que marcaram o século XX, assim como nas perspectivas educacionais para o século XXI. No pensamento moderno, muitos são as suas conotações que revelam uma profunda relação com as teorias e contexto sociopolítico em que são utilizadas. Portanto, o uso corrente do termo autonomia nos discursos relativos à educação devem ter o cuidado de trazer à tona as dimensões e características a que ele se vincula com vistas a um melhor entendimento e clareza da discussão.

No presente artigo, apresentamos parte do resultado da pesquisa realizada na dissertação sob autoria e coordenação das autoras supracitadas. Nosso enfoque neste texto tem como objetivo principal divulgar, esclarecer e avançar em alguns pontos essenciais para a compreensão do conceito de autonomia em EaD e das peculiaridades que a educação mediada por tecnologias apresenta.

\section{METODOLOGIA}

A metodologia empregada para investigar o conceito de autonomia na Educação a Distância foi uma abordagem de cunho qualitativo e de natureza descritiva e explicativa. Para tanto, realizamos uma pesquisa bibliográfica, de modo a delinear a utilização do termo de forma geral no campo da educação a distância, para em seguida, discorrermos sobre como o conceito de autonomia se desenvolve e se vincula com outras características fundamentais da educação mediada pelas tecnologias de informação e comunicação (TICs), pautando-se em diferentes teorias de autores que são referências na área.

\section{RESULTADOS}

A EaD sempre esteve vinculada à premissa de maior liberdade e engajamento do estudante. Isto se deve ao fato da não presencialidade incutir a ideia de maior exigência e responsabilidade para que o aluno evolua nos estudos. 
A modalidade a distância, utilizada inicialmente por meio de cursos por correspondência, era marcada por uma forma instrucional de aprendizagem que exigia muito do aluno. Naquele contexto, a autoaprendizagem foi de fato uma característica predominante em cursos que não dispunham de ferramentas tecnológicas e de assistência contígua.

Nos anos 1970, teve início uma nova fase para a EaD em nível internacional. A ferramenta de comunicação utilizada na modalidade passa da correspondência para a comunicação de massa por meios eletrônicos analógicos, como o rádio e a televisão. Como consequência, houve importantes mudanças pedagógicas que proporcionaram diferentes maneiras de se pensar novas abordagens, as quais, por sua vez, também modificaram a maneira de se pensar a EaD.

Dentre as principais características desse momento estão:

"[...] o considerável progresso na criação e no acesso à educação superior para grupos maiores de adultos, experimentação pedagógica, a aplicação cada vez maior de tecnologias educacionais, a introdução e a manutenção de aprendizado aberto e permanente e o inicio da educação superior em massa" (PETERS, 2009, p. 32).

Esses avanços para a modalidade trouxeram reconhecimento e intenso financiamento pelos governos no exterior, o que criou e fortaleceu as universidades a distância autônomas que atendem a milhões de estudantes em todo o mundo. O impacto da crescente utilização da informatização e comunicação digital repercutiu em uma revolução pedagógica e em novos paradigmas sobre a aprendizagem. O desenvolvimento da concepção de autonomia em EaD surge nesse contexto, no qual se tem como perspectiva a aprendizagem online desenvolvida em Ambientes Virtuais de Aprendizagem (AVAs) abertos, centrados no alunos, interativos e flexíveis quanto ao currículo.

Um pioneiro no estudo de aprendizagem de adultos e que destaca o aspecto autodiretivo de aquisição de conhecimento é Malcom Knowles. Em seus estudos e pesquisas, o autor trata da aprendizagem de adultos como um campo específico da ciência denominado andragogia. Nessa teoria, os adultos são autônomos e autodirigidos. Isto significa afirmar que preferem dirigir sua própria aprendizagem, estarem ativamente envolvidos nos estudos e, para tal, definir objetivos e assuntos de seu interesse. Deste modo, sua concepção de autoaprendizagem, em sentido mais amplo, descreve um processo

[...] em que os indivíduos tomam a iniciativa, com ou sem a ajuda de outros, diagnosticando suas necessidades de aprendizagem, formulando objetivos de aprendizagem, identificando os recursos humanos e materiais para a aprendizagem, escolhendo e implementando estratégias de aprendizagem 
apropriadas, e avaliando os resultados da aprendizagem (KNOWLES, 1975, p.18, nossa tradução).

Já a teoria de Moore combina a perspectiva de EaD adotada por Peters, a qual entende esse modelo como um sistema industrial estruturado, e a perspectiva de Wedemeyer, em que a relação é centrada no aluno a na interatividade entre os participantes. Esta última ficou conhecida, desde 1986, como a teoria da Interação a Distância (Transactional Distance) (MOORE; KEARSLEY, 2007).

Nas palavras de Moore,

A interação que chamamos de educação a distância, ocorre entre indivíduos que são professores e alunos, em um ambiente que tem a especial característica de separação entre eles, e um consequente conjunto de ensino diferenciado e de comportamentos de aprendizagem (MOORE, 1991, p. 3, nossa tradução) ${ }^{1}$.

A primeira questão que devemos observar é que na teoria da Interação a Distância, a distância aí considerada não é simplesmente geográfica, mas um fenômeno pedagógico (MOORE; KEARSLEY, 2007). O autor exemplifica que programas a distância baseados na comunicação entre professores e alunos e que permitem um diálogo constante entre eles apresentam um baixo nível de distância transacional. Já programas altamente estruturados, rígidos e pouco capazes de se adaptar às necessidades dos indivíduos, sejam eles a distância ou presenciais, são transacionalmente distantes do aluno.

Moore (1991) apresenta dois procedimentos especiais de ensino que determinam a extensão da distância em um programa. Vale salientar que esses não são tecnológicos, mas relativos às variáveis no ensino e na interação do ensino e da aprendizagem. Os dois conjuntos de variáveis são o diálogo e a estrutura do curso.

Diálogo não é o mesmo que interação. A interação é importante para que o diálogo ocorra, mas para que este se efetive ela precisa ter uma finalidade: ser construtiva e valorizada pelos participantes.

Em relação à estrutura, Moore e Kearsley (2007) assinalam que um aspecto que deve ser repetidamente enfatizado é que, na análise de programas específicos, há muito mais aspectos envolvidos além da tecnologia empregada. A tecnologia não determina se um curso é muito ou pouco estruturado. O modo como o projeto é pensado e a rigidez ou flexibilidade que ele

\footnotetext{
${ }^{1}$ Segue o original: "The transaction that we call distance education occurs between individuals who are teachers and learners, in an environment that has the special characteristic of separation of one from another, and a consequent set of special teaching and learning behaviors" (MOORE, 1991, p. 3). 
apresenta também estão relacionados ao modo de organização em que o sistema funciona (MOORE, 1991).

Outro enfoque sobre a autonomia relacionado ao diálogo e à estrutura do modelo é apresentada por Randy Garrison. Sua discussão enfoca o princípio da proficiência, que se reporta à capacidade do aluno construir significado e ter disposição para iniciar e persistir em uma iniciativa de aprendizagem.

O aluno deve assumir a responsabilidade por criar significado a partir do conteúdo assimilado ou incluir ideias e conceitos novos em sua estrutura de conhecimento já existente. A partir daí, o conhecimento deve ser compartilhado como forma de comunicação recíproca que visa confirmar a compreensão e gerar conhecimento válido. Esse movimento intelectivo resulta no que o autor denomina aprendizado em colaboração e na construção social do conhecimento (MOORE; KEARSLEY, 2007).

Essa perspectiva construtivista e colaborativa da aprendizagem se reforçou com os avanços tecnológicos, permitindo que a $\mathrm{EaD}$ pudesse se desenvolver rumo não apenas à veiculação de conteúdos considerados como formas de transmissão, mas, sobretudo, consolidando formas significativas de interação.

Contudo, na visão de Garrison, a interação não basta. Presença cognitiva e social são noções desenvolvidas para que haja qualidade efetiva de comunicação. Conforme o autor, "Interação em um ambiente como esse vai além da interação social e da simples troca de informações" (GARRISON, 2005, p. 134, nossa tradução) ${ }^{2}$. A interação deve ser estruturada e sistemática, de maneira que se alcancem resultados de aprendizagem específicos. Além do mais, pela comunicação no contexto educacional a distância ser veiculado por meios artificiais, é necessário que se desenvolva essa presença social. Assim, a autonomia do educando passa a ser entendida, não apenas no que diz respeito ao aluno individualmente, mas a características importantes para o bom relacionamento e construção de conhecimentos colaborativos.

\section{DISCUSSÃO}

A concepção de autonomia em EaD desenvolve-se enquanto perspectiva de aprendizagem situada em Ambientes Virtuais de Aprendizagem (AVAs) abertos, centrados nos alunos, que pressupõem um modo de relação interativa com os conteúdos e uma estrutura flexível quanto ao currículo.

\footnotetext{
2 Segue o original: "Interaction in such an environment goes beyond social interaction and the simple exchange of information" (GARRISON, 2005, p. 134). 
Podemos observar, nos apontamentos sobre as teorias apresentadas, a preocupação em se compreender as variáveis do processo educacional mediado pelas tecnologias. Diferentes questões são priorizadas em cada uma delas, como a relação entre o desenvolvimento da autonomia e o perfil do aluno, a estrutura do curso e o o modo como se dá o relacionamento com as ferramentas disponíveis.

O mérito de cada uma reside na tentativa de construção de uma teoria da educação a distância que possa organizar fatos e conceitos compartilhados, para que tornem possível a discussão, a análise e a crítica na área, evitando questões vagas, ou já respondidas.

\section{CONCLUSÃO}

Para finalizar, ressaltamos que as concepções de autonomia em EaD possuem, assim como outros termos na área, o seu significado estendido e transformado. A informatização no campo da aprendizagem traz consequências que diferem em muitos aspectos do conhecimento tradicional. Defrontamo-nos com formas diferentes de transmissão e relação com informações e conhecimento que implicam no que Peters denomina um "lidar com" (2009, p. 353); esses conteúdos que trazem novas formas de comportamentos de aprendizagem que recebem um significado anteriormente desconhecido.

Mais do que isso, para que ocorra um domínio do gerenciamento do conhecimento no campo da aprendizagem online, um objetivo pedagógico primordial é o esclarecimento sobre o modo como se dá esse conhecimento para que as pessoas tenham domínio dos processos e mecanismos intrínsecos a essa diferente maneira de se aprender.

\section{REFERÊNCIAS}

GARRISON, Randy; CLEVELAND, Martha. Facilitating Cognitive Presence in Online Learning: Interaction Is Not Enough, American Journal of Distance Education, v. 19, n. 3, p. 133-148, 2005. Disponível em: <http://www.tandfonline.com/doi/abs/10.1207/s15389286ajde1903_2\#.U07Ev15> Acesso em: 16 abr. 2014.

KNOWLES, M. S. Self-Directed Learning: a guide for learners and teachers, Englewood Cliffs: Prentice Hall/Cambridge, 1975.

MOORE, Michael G. Distance Education theory. Editorial written for the upcoming issue 5.3. American Journal of Distance Education, Pennsylvania, USA, 1991.Disponível em: <http://learningdesign.psu.edu/index.php/section/deos2/volume_1_1991>. Acesso em: 14 maio 2014. 
MOORE, Michael G.; KEARSLEY, Greg. Educação a Distância: uma visão integrada. São Paulo: Thompson Learning, 2007.

PETERS, Otto. A Educação a distância em transição: tendências e desafios. São Leopoldo, RS: Ed. Unisinos, 2009. 